to rest, when I was summoned to attend on Mrs. H., a lady who lired some four miles from my residenoe. She had only spoken to me two days previously, and then told me that she expected early in February 1856. She is a spare, feeble woman, aged 31, and has had three children; the first being a breech presentation.

On my arrival, I found that ever since she had seen me on the 14th, she had suffered more or less from slight pains recurring at uncertain intervals; that at two o'clock in the afternoon there was a slight show, and from that time up to my coming she had been slowly getting worse. On examination, I found the os uteri dilated to about the size of a half-crown, and the membranes slightly protruding. I was, however unable to detect the presentation. The pains not being violent, and recurring only every twenty minutes, I went down stairs and slept for three hours on the sofa. On making a second examination, I found that the os had dilated considerably, and that the bag of waters was coming down nicely. I was still unable, however, to detect the presentation. I now felt convinced that there was some malpresentation. After several attempts to discover what it was, I at last detected an arm lying across the mouth of the womb. I immediately ruptured the membranes, and without any difficulty succeeded in turning the child. The natural efforts of the uterus expelled it in three pains. The child had evidently been dead some hours, and was not more than seven months. I then, according to my invariable custom, placed a bandage moderately tight round the abdomen, and waited for a pain to expel the placenta. I had waited some twenty minutes, when there came a frightful gush of blood, which soaked through ererything, and made my patient faint. I immediately grasped the uterus through the abdominal parietes, as firmly as I could, and after thus checking it a good deal, I introduced $\mathrm{my}$ hand into the womb, and found the upper portion of the placenta firmly adherent to its fundus. After considerable difficulty, I succeeded in detaching and removing it. The hæmorrhage then stopped, but the uterus remained flaccid and very little contracted. I then used friction to endeavour to restore its action, and while thus engaged, another violent gush took place. I again grasped the uterus with one hand, and with the other kept coustantly applying cold wet napkins to the vulva, but though abated, it kept on dribbling, and my patient became pallid and faint. I directed the nurse to give her the yolk of an egg in about two tablespoonfuls of brandy, and this somewhat revived her. For about two hours I felt the greatest anxiety for her safety, but at length the uterus began to contract, and with this the hrinorrhage became less. During the two hours I was grasping the womb, I gave her three eggs and six ounces of brandy. After the flooding had somewhat abated, I well padded a teasaucer with soft linen, and bound it firmly round the abdomen, so that the saucer should, as it were, grasp the womb. I remained with her two hours longer, when finding no return, I gave her a simple effervescing saline, and left her at 10 A.M. on the 17th. I saw her again at I P.M., and again at 8 P.M., and found her each time progressing most satisfactorily. She continued the effervescing medicine throughout the day. On my visit next morning I found she had slept very comfortably. She had passed her urine freely. The pulse was 70, and the tongue clean and moist.

Remarks. Cases of this kind cause one a good deal of anxiety. During the time I was resident-accoucheur at St. Thomas's Hospital, I met with sereral, but none where so much blood was lost as in this case. The only thing to guard against in administering stimulants and nourishment is not to exhibit them too early, for syncope, as is well known, is farourable so long as it does not go too far, the force of the circulation being much less, and the blood having a greater tendency to coagulate; but when this syncope continues, I believe egg and brandy to be the sheet anchor of our treatment. The use of opium I much dislike; nor am I partial to ergot. The less one meddles with either the better.

\section{TWO LARGE CALCULI IN THE BLADDER, PRODUCING ULCERATION AND PER- FORATION, AND FOLLOWED BY EXTRAVASATION OF LRINE.}

By W. THONAS BELL, Esq., Great Grimsby.

Joun DAwson, aged 34, a porter at Thoresby station, on the Great Northern Railway, of an exsanguine, sallow, and unhealthy apnearance, light sandy hair, blue eyes, and formerly of very intemperate habits; born in Norfolk, where he resided for a few years; afterwards joined a regiment ordered to India ; he remained there for several years, when he returned to England: he has resided in Lincolnshire for the last twelve months.

From childhood, he has suffered at times from irritation of the bladder. While in India, he was invalided for bladder symptoms. Up to the last six months, he has had no oceasion to pass his urine oftener than in moderate health, and has not suffered from pain in micturition; but of late the usual symptoms of calculus have presented themselves, as frequent micturition, pain, immense deposit in urine upon standing, containing a quantity of soft mortary matter, adhering to the urethra.

Dec. 3rd, 1855. I was sent for to visit him, and found the following symptoms present: ferer; small, weak, quick pulse; white coated tongue; great pain in pubic region, increased by micturition; urine occasionally dribbling away in the bed, from loss of power over the bladder; his urine contained a large quantity of mucus, of a pink colour, and highly offensive ammoniacal odour, with distinct portions of mortary matter; loss of appetite, and sleepless nights. I ordered him the following remedies:-Twelve leeches beneath the pubes, to be followed by warm fomentations; a dose of castor oil and laudanum ; and, after its operation-

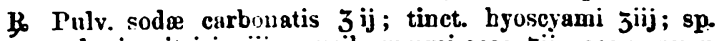
ætheris nitrici ${ }^{i i j}$; mucil. gımmi acac. 当 ; aqua puræ q. s. Ft. mist. $\xi$ xij, cujus capiat ij cochlearia magna quartis horis.

Bo Pulv. opii gr. ij; conf. rosæ can. q. s. Ft. pil. ij horâ somni sumend.

Dec. 8th. The above remedies he perserered in up to this date, when he had got decidedly worse; I therefore, for my own satisfaction and that of his friends, sounded the bladder; and, from the intense spasm, and the bladder being perfectly empty, had some difficulty in detecting the calculus. I attempted to inject some warm water, but it would not retain half an ounce, causing intense suffering.

Dec. 12th. Losing ground very fast; urine passes away involuntarily in bed; excoriation of penis and scrotum; pulse excessively quick and very weak; not much pain; nasty urinary smell about his perspiration; cannot take any food; sunken features, although in good spirits.

Bo Acid. nitrici diluti $\bar{j}$ iv; tinct. hyoscyami $\bar{j}$ iv; ext. pareiræ brave $3 \mathrm{j}$; decoct. pareiræ bravæ $3 \times \mathrm{x}$. M. Ft. mistura cujus capiat ij cochlearia magna ter die.

B Pulv. opii gr. ij; pil. hydrarg. gr. iij. Ft. pil. ij hora somni sumend.

Dec. 14th. Much worse, gradually sinking.

Dec. 15th. Violent pain in abdomen; collapse ; perfect suppression of urine. 'I passed a catheter into his bladder, and felt a large stone. Ordered brandy and opium.

Dec. 16th. Died this morning.

Pobt Mortex Examination, twenty-four hours after death. Body exsanguine, yellow, and much wasted; rigor mortis slight; urinary smell from body. Upon openimg the abdomen, the small intestines were much inflamed, and glued together by recent lymph. Urine in cavity of abdomen.

Bladder. Quite contracted; walls thickened; internal coat soft, and covered with purulent matter. Just on the right side of base of trigone there was an ulcerated opening: through this the finger could readily bo passed from within outwards (quite gangrenous): within its cavity were contained two calculi, weighing four ounces and one dreohmy the smallest was about the size of a walnut. 
Kidncys. Right greatly hypertrophied with purulent infiltration. Left contained a small abscess; it was also enlarged csosiderably.

Other regions of body not examined.

RExAREs. There are many features of interest throughout in this case worthy of publication. The patient, born in Norfolk, the greatest stone county in England, departs to India, where stone is also very common. He has been a hard drinker, accounting for his renal disease. The very great size of the calculus, which must have been sereral years in forming, and the fact that he only sought medical advice about three weeks before his death, show how slight his symptoms must comparatively have been. His death was no doubt materially hastened by a ruptured bladder, extensive peritonitis, disease of both kidneys, suppression of urine, and circulation of urinary salts. Upon my first and succeeding visits, an operation for lithotomy was perfectly impracticable; and, from the insight at the post mortem, I consider myself truly fortunate that I had not been called upon to operate, as he most certainly would have died under the operation.

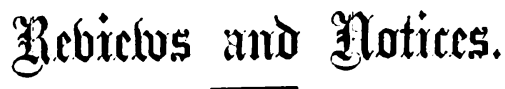

The Influevce of Tropical Climates on European Constiturions. By Jayes Ranald Martin, F.R.S., Surgeon Bengal Army, retired, late Presidency Surgeon, and Surgeon to the Native Hospital, Calcutta. pp. 599. London: 1855.

SoMe men write books that they may obtain reputation and practice, but without having acquired sufficient experience to secure for themselves the approbation of the professional reader. Other men write books which contain alone the results of extended observation and long familiarity with disease, not for the sake of emolument, but that they may impart something to the general fund of medical knowledge. And their opportunitics of observation, and their experience have been such, that the opinions they express carry with them the stamp of authority.

It is with the latter class of medical literature that we prefer to associate, and of this class the work before us is an admirable specimen.

After a long residence in the presidency of Bengal-after an intimate acquaintance with the features of the climate and soil of that important and extensive territory-after many years of active employment, with his regiment, on the field of battle, in the public hospitals of Calcutta, and in private practice in India, Mr. MA BTIm returned to this country, apparently broken down in health and constitution, from the effects of hard work and exposure under a tropical sun. But the climate of England, and the tonic of "home", added to the vigour of a Highlander, soon restored him to health and to activity. Not content to pass the remainder of his days in idleness, Mr. Martin was soon occupied in preparing, with the late Dr. James Johnson, a new edition of the work upon "The Influence of Tropical Climates on European Constitutions"-and what two better names could have been associated in such a work?

How far that volume has been appreciated, is best indicated by the demand now made for a serenth edition. But the death of Dr. James Johnson, and " the advancing knowledge of the day", rendered something more than another edition necessary, and a new work is, therefore, the result ; "for", says Mr. Martin, "he has ventured to recast and rewrite the entire work."

We thank him much for his labour, and for two reasons; not only are the characteristics of the climate of the tropics, and its effects upon the European constitution, amply considered-conditions chiefly interesting to the medical offcers of the sister services-but to the practitioner at home the work is rendered extremely valuable, as it embraces the consideration of the diseases of the returned Indian, and the treatment to be pursued in his case during his reaidence in this country. Indeed, these two fentures of the work are 80 important, that we propose to consider them separately, as much so as if the work were divided into distinct volumes, each embracing its proper subject.

The first chapters of the work are devoted to the characteristics of the climate of Calcutta and Bengal, to the influence of seasons and soils on the health of the white man and the native, and to the mortality resulting from these causes, as shown by the returns of regiments in the service of the Crown and of the Company.

It is impossible, in the space allotted to us, that we can do sufficient justice to these considerations-most carefully weighed and admirably put together in the work before us. We can do little more than call the attention of our readers to the numerous points of importance, leaving them to peruse, at their leisure, the excellent observations relating to climate, soil, elevation, etc., observations which apply with equal force to all sanitary measures in this as well as in all tropical climates:-

"The importance, in a sanitary point of view, of attention to the subject of elevation, is exemplified", says our author, $\omega$ in the fact that plague in Egypt, yellow ferer in the West, and marsh remittent in the East and West, have never been known to ascend to any considerable height."

The fens of Lincolnshire and the swamps of the Mississippi might have been added to the list, if more evidence was necessary, to indicate the fertile sources of intermittent from the low levels of their surface, and the humid conditions of their soil.

These considerations point to the high importance of looking far beyond the mere treatment of disease; of endeavouring to ascertain the predisposing causes of maladies, and of endeavouring to effect their prevention or secure their removal; - considerations which it is our duty to examine maturely at all times and in all seasons, and considerations which, at this very period, must be carefully gone into by those to whom are entrusted the appointments of " officer of health".

But elevation of surface, though an important element in the selection of habitations, is not alone a securily against certain forms of disease, and we would particularly draw attention to some observations Mr. Martin makes regarding the influence of "ferruginous soils" upon the production of fever. Such soils existing in hill countries have been proved as noxious and fatal to the inhabitants as the lowest and most swampy levels. In the hill ranges of Southern India, Dr. Heyne found that "iron hornblende occurs in such quantity, that all the rivulets, public roads, indeed all hollows along the hills, were filled with its sand, from which, also, all the iron in this part of the country is manufactured ;" and yet, in these high ranges, the "malignity of the fever" which attacks the European is notorious.

The influences of heat and cold on the system of the European while in the tropics are carefully noted; and some good practical hints given, to which the English practitioner may with advantage pay attention.

"As regards the influence of the formen, there are trio classes of persons to whom", says Mr. Martin, "the climate of India seems genial, the weak-chested, as they are called in England, who are of a scrofulous habit, but in whom pulmonary disease has not yet actually declared itself. These are saved by going to India; and I have known many persons in the curable stage of consumption, that is, labouring under the preceding stage, or that of ' tuberculous cachexy', enjoy good health in Bengal, and survive their brothers and sisters at home. The fate of those, on the other hand, who go to the East with suppurating tubercles, or even in the stage approaching to it, is only precipitated. Persons of phlegmatic habit, also, with dyspepsia, languid circulation, and cold extremities, seem to have better health there than in Europe."

But what of the cold season? "From the lst of November to the end of February the weather is settled and agreeable to persons in health; but to the delicate and sickly the altered balance of circulation and nervous function occasions much discomfort. The monsoon keeps 